\title{
El papel de los ácidos grasos libres en la resistencia a la insulina
}

\author{
José Gustavo Vázquez-Jiménez¹, Adriana Roura-Guiberna², Luisa Reyna Jiménez-Mena² \\ y Jesús Alberto Olivares-Reyes ${ }^{2}$ \\ Laboratorio de Transducción de Señales, Departamento de Bioquímica, Centro de Investigación y de Estudios Avanzados del Instituto Politécnico \\ Nacional, Ciudad de México, México
}

\section{Resumen}

Los ácidos grasos libres son componentes nutricionales esenciales y estudios recientes los identifican como moléculas de señalización en varios procesos fisiológicos. Actualmente se ha evidenciado que valores elevados de ácidos grasos libres, en particular los ácidos grasos saturados, pueden estar asociados a la resistencia a la insulina en pacientes obesos con diabetes mellitus tipo 2. El estado de resistencia a la insulina tiene un rol importante desde el punto de vista clínico ya que se encuentra asociado a varias enfermedades, entre las que se incluyen la diabetes mellitus tipo 2, dislipidemias y anormalidades cardiovasculares. Estudios recientes han propuesto diversos mecanismos moleculares a través de los cuales estos lípidos pueden alterar la vía de señalización de la insulina. El propósito de esta revisión es resaltar los avances recientes en el estudio del efecto de los ácidos grasos como moduladores de la respuesta a la insulina.

PALABRAS CLAVE: Ácidos grasos. Resistencia a la insulina. Receptor de insulina. Sustrato del receptor de insulina.

\begin{abstract}
Free fatty acids are essential nutritional components and recent studies identified them as signaling molecules in various physiological processes. It has now been shown that high levels of free fatty acids, particularly saturated fatty acids, may be associated with insulin resistance in obese patients with type 2 diabetes mellitus. Insulin resistance is important in clinical since it is related to various diseases including type 2 diabetes mellitus, dyslipidemia, and abnormalities at cardiovascular level. Recent studies have proposed different molecular mechanisms by which these lipids may alter the signaling pathway of insulin. The purpose of this review is to highlight recent advances in the study of the effect of free fatty acids as modulators of insulin response.
\end{abstract}

KEY WORDS: Fatty acids. Insulin resistance. Insulin receptor. Insulin receptor substrate.

\author{
Correspondencia: \\ Jesús Alberto Olivares-Reyes \\ Avda. Instituto Politécnico Nacional, 2508 \\ Col. San Pedro Zacatenco \\ C.P. 07360, Ciudad de México, México \\ E-mail: jolivare@ cinvestav.mx
}

Fecha de recepción en versión modificada: 01-07-2016

Fecha de aceptación: 08-08-2016

DOI://dx.doi.org/10.24875/GMM.17002714
Gac Med Mex. 2017;153:852-863

Contents available at PubMed www.gacetamedicademexico.com 


\section{Introducción}

La resistencia a la insulina es una condición sistémica en la que las células dejan de responder a esta hormona. Bajo esta condición se alteran funciones metabólicas muy importantes de la insulina en los tejidos hepático, muscular y adiposo, principalmente, como la incorporación de glucosa y la síntesis de glucógeno, de lípidos y de proteínas, entre otros efectos ${ }^{1,2}$. Se encuentra estrechamente vinculada al síndrome metabólico, la obesidad y al desarrollo de diabetes mellitus tipo 2 (DM2). Según las estadísticas más recientes de la Organización Mundial de la Salud y de la Federación Internacional de Diabetes, más de 1500 millones de personas en el mundo padecen obesidad o sobrepeso, mientras que la diabetes afecta a más de 387 millones, cifra que para el año 2035 alcanzará cerca de los 600 millones si no se toman las medidas adecuadas (http:// www.who.int/en/index.html; http://www.idf.org).

A la fecha se han identificado diversos factores que pueden inducir resistencia a la insulina, entre los que destaca el incremento en plasma de la concentración de ácidos grasos libres (AGL), seguido por una alterada utilización de los lípidos por el tejido muscular ${ }^{3}$. Este fenómeno, común en pacientes obesos, se ha observado en estudios clínicos y se ha corroborado en investigaciones moleculares.

Entre los mecanismos implicados en la resistencia a la insulina por acción de los ácidos grasos (AG) se encuentran alteraciones en la vía de la cinasa PI3K, la producción y la acumulación de ceramidas, la activación de la proteína cinasa $C$ (PKC), la generación de especies reactivas de oxígeno (ERO), el estrés del retículo endoplásmico (RE) y la rigidización membranal.

\section{Acciones de la insulina}

La insulina es la principal hormona anabólica del organismo; controla funciones energéticas cruciales, como el metabolismo de glucosa, lípidos y proteínas. Uno de sus cometidos más importantes es la regulación de la homeostasis de la glucosa, ya que permite su entrada y almacenamiento en el tejido muscular y adiposo, y favorece su almacenamiento e inhibe su producción en el hígado. Además, la insulina promueve la división y el crecimiento celular mediante sus efectos mitogénicos.

La insulina activa receptores específicos de la superficie membranal conocidos como receptores de insulina, los cuales pertenecen a la familia de receptores con actividad intrínseca de cinasas tirosinas. Tras la unión de la insulina, el receptor se autofosforila y a su vez fosforila y recluta proteínas adaptadoras, como el sustrato del receptor de insulina (IRS). Los IRS-1 e IRS-2 constituyen los dos sustratos e intermediarios más comunes en la etapa inicial de propagación de la señal de insulina, que organizan complejos moleculares y desencadenan cascadas de señalización intracelular ${ }^{4}$. Entre las diferentes cinasas activadas por la vía de PI3K se encuentra la cinasa Akt, la cual desempeña un papel muy importante en las funciones metabólicas de la insulina, principalmente en la captación de glucosa en el músculo y el tejido adiposo. Akt participa en la translocación de la proteína transportadora de glucosa-4 (GLUT4) de vesículas intracelulares a la superficie celular para incrementar la captura de glucosa. La insulina también participa en la inhibición de la gluconeogénesis y favorece la síntesis de glucógeno, lípidos y proteínas en tejido hepático, adiposo y muscular, respectivamente1 (Fig. 1).

Por su parte, las acciones mitogénicas de la insulina se llevan a cabo a través de la proteína adaptadora Shc, que activa la vía de las cinasas activadas por mitógeno/Ras (MAPKs/Ras) ${ }^{1}$ (Fig. 1).

\section{Ácidos grasos y resistencia a la insulina}

Las causas moleculares de la resistencia a la insulina son diversas: involucra defectos en la unión de la insulina a su receptor y alteraciones posteriores a dicha unión. Entre estas se encuentran la disminución en el número de receptores de insulina y de la actividad de las cinasas PI3K y Akt, defectos en la expresión y la función del transportador GLUT4, y aumento de la fosforilación en residuos de serina/ treonina de proteínas como el receptor de insulina 0 IRS, siendo este último mecanismo clave en el desarrollo de la resistencia a la insulina. Lo anterior puede ocasionar alteraciones en la asociación del receptor y de su sustrato a otras proteínas, disminución del estado de fosforilación en tirosinas de ambas proteínas, y disminución de su activación y su degradación ${ }^{1}$. Estos mecanismos de resistencia a la insulina se han asociado a altas concentraciones de AGL en plasma.

Los AG son ácidos carboxílicos altamente anfipáticos que constan de cadenas hidrocarbonadas de una longitud de entre 4 y 26 átomos de carbono, las cuales no presentan ramificaciones ${ }^{5,6}$. El término AGL se 


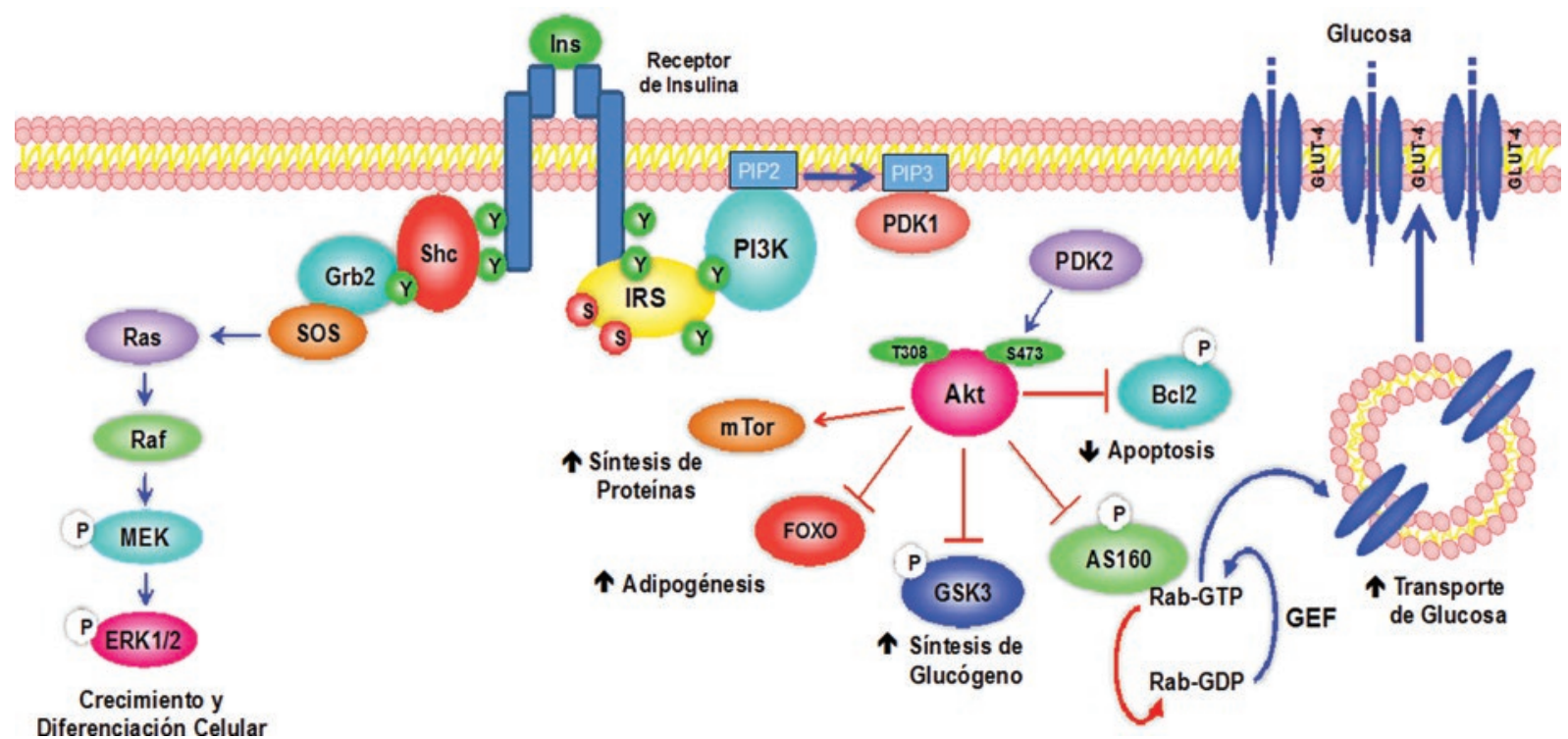

Figura 1. Vía de señalización de la insulina. Después de ser activado por la insulina, el receptor recluta y fosforila principalmente dos proteínas adaptadoras: IRS y Shc. Estas proteínas organizan complejos moleculares que desencadenan diferentes cascadas de señalización intracelular. Entre las vías mediadas por IRS se encuentran la de PI3K/Akt, la cual tiene un papel crucial en la activación y la regulación de diversos eventos metabólicos, que incluyen el transporte de glucosa y la síntesis de glucógeno, proteínas y lípidos. En el caso de la proteína Shc, esta se asocia a la activación de la vía de las cinasas activadas por mitógeno, MAPK, que regula funciones proliferativas y de crecimiento (modificada de Olivares-Reyes ${ }^{1}$ ). Akt: proteína cinasa B; AS160: sustrato de Akt de 160 kDa; GLUT-4: transportador de glucosa 4; GSK3: proteína cinasa de la glucogeno sintasa 3; IRS: sustrato del receptor de insulina; PDK1: proteína cinasa dependiente de fosfoinositidos 1; PDK2: cinasa dependiente de fosfoinositidos 2; PI3K: cinasa de fosfatidilinositol 3; PIP2: fosfatidilinositol-4,5-bifosfato; PIP3: fosfatidilinositol-3,4,5- trisfosfato.

refiere a los $A G$ que no se encuentran esterificados, y estos provienen principalmente del metabolismo de los triacilglicéridos y de los fosfolípidos. Dependiendo de la presencia o no de enlaces dobles, estos se clasifican en dos grandes grupos: los que contienen únicamente enlaces simples son conocidos como ácidos grasos saturados (AGS), en los que los hidrógenos se hallan dispuestos en posición trans; y los AG que cuentan con enlaces dobles, que son denominados insaturados y pueden encontrarse en configuración tanto cis como trans, aunque esta última es poco común en la naturaleza. A los AG insaturados que solo contienen un doble enlace en su estructura se les llama monoinsaturados, mientras que a los que contienen dos o más se les llama poliinsaturados ${ }^{5,6}$.

Los AG desempeñan importantes funciones biológicas en los seres vivos; actúan como una fuente importante de energía para la mayoría de los tejidos del cuerpo, entre los que se incluyen el corazón, el músculo esquelético y el hígado7. Además, poseen una amplia variedad de funciones biológicas, como ser parte estructural de la membrana celular (siendo esenciales para su fluidez y funcionalidad) y actuar como moléculas de señalización ${ }^{6}$. Los AG son usados como la principal fuente energética del organismo durante periodos de ayuno o cuando no existe suficiente glucosa. Sin embargo, cuando los valores de
AGL son anormalmente altos en el organismo, como sucede en la obesidad, se induce un estado de lipotoxicidad que lleva a la activación de distintas respuestas celulares asociadas a esta toxicidad, entre las que se encuentran estrés oxidativo, estrés del RE, apoptosis e inflamación ${ }^{6}$. Entre los AGL identificados como principales causantes de estas respuestas celulares, se encuentran los AGS.

La primera evidencia de que la elevación de los AGL desempeña un papel importante en el desarrollo de resistencia a la insulina en el músculo fue sugerida por Randle, et al. ${ }^{8}$ en 1963, basándose en observaciones de que una alta concentración de AGL en plasma se asocia comúnmente con diabetes y otros trastornos del metabolismo de los hidratos de carbono. A la fecha se han descrito diversos mecanismos moleculares por los que los AGL inducen resistencia a la insulina, los cuales se describen a continuación.

\section{Resistencia a la insulina inducida por ácidos grasos: participación de la PKC}

Los AGL, que a menudo se encuentran elevados en los individuos obesos, tienen un papel causal muy importante en la asociación entre obesidad y resistencia a la insulina ${ }^{9}$. Aunque los mecanismos por los que los AGL inducen resistencia a la insulina han sido 


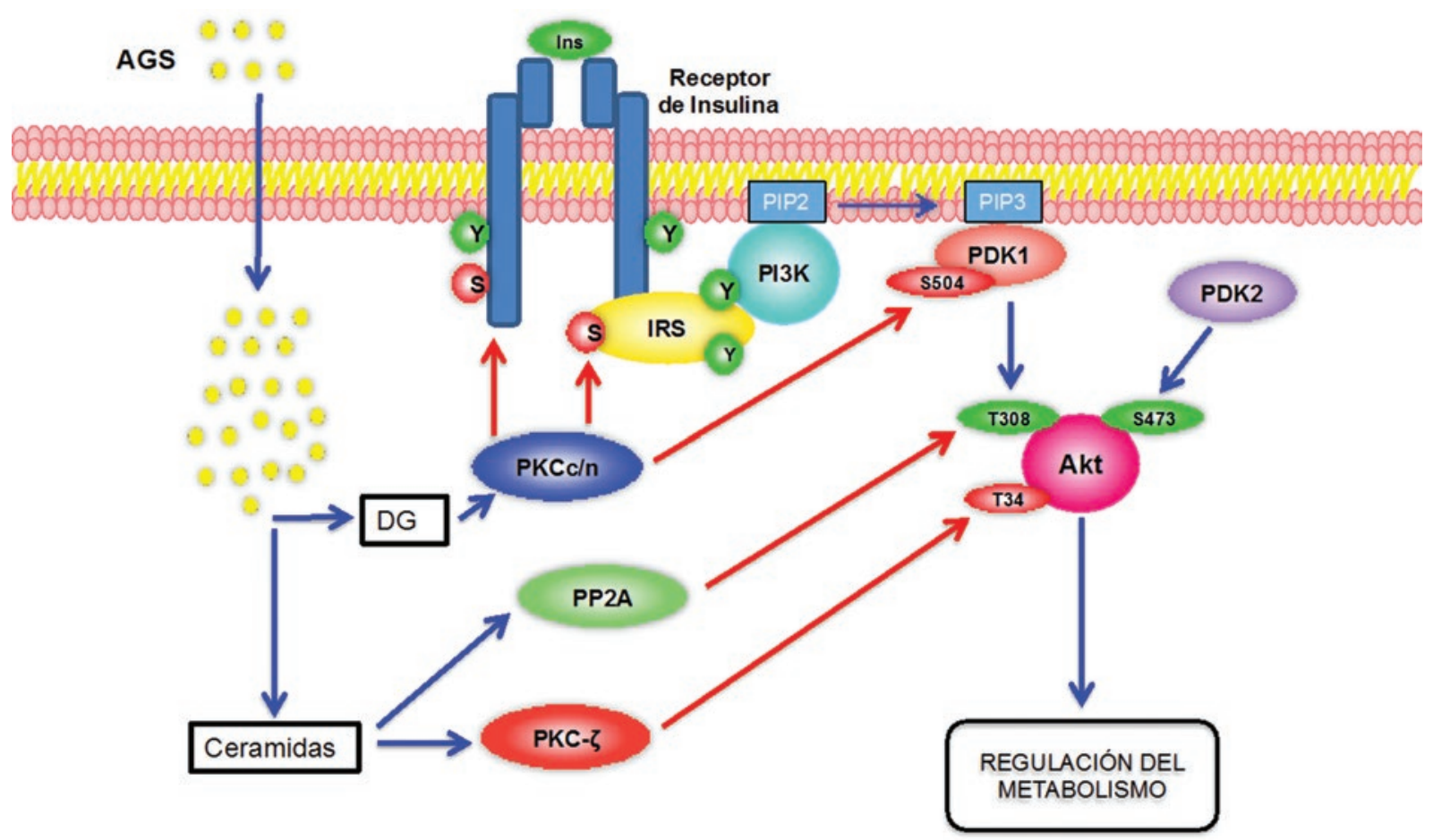

Figura 2. Diacilglicerol y ceramidas como mediadores de la resistencia a la insulina por AGS. El metabolismo de los AGS lleva a la formación de intermediarios, como el DAG y las ceramidas. El DAG es un potente activador de las PKC clásicas y nuevas, las cuales participan en la regulación negativa de la señalización de la insulina, fosforilando al receptor y a IRS en residuos de serina. Adicionalmente se han identificado otras dianas de fosforilación de PKC, como la enzima PDK1, alterando su actividad enzimática y afectando la posterior activación de Akt. Los AG también favorecen la síntesis de ceramidas que activan a PP2A, una fosfatasa que desfosforila a Akt en la treonina 308, y a PKC- $\zeta$ que fosforila a Akt en la treonina 34. En ambos mecanismos, la actividad de Akt es inhibida, alterando la regulación de las vías metabólicas de la insulina AGS: ácidos grasos saturados; Akt: proteína cinasa B; DG: diacilglicerol; Ins: insulina; IRS: sustrato del receptor de insulina; PDK1: proteína cinasa dependiente de fosfoinositidos 1; PDK2: cinasa dependiente de fosfoinositidos 2; PI3K: cinasa de fosfatidilinositol 3; PIP2: fosfatidilinositol-4,5-bifosfato; PIP3: fosfatidilinositol-3,4,5-trisfosfato; PKCc: proteína cinasa C clásica; PKCn: proteína cinasa C nueva; PP2A: fosfatasa de proteína $2 A$; S: serina; T: treonina; Y: tirosina.

parcialmente identificados, diversas evidencias sugieren la participación de la PKC, que es activada a través de diferentes mecanismos.

Actualmente se conoce que, como consecuencia del exceso de lípidos de la dieta o en la obesidad, se presenta un incremento excesivo de estos ácidos en el torrente sanguíneo, que excede la capacidad de almacenamiento y oxidación, provocando que los AGL y los intermediarios de su metabolismo (como el ácido linoleico, el diacilglicerol [DAG], el ácido fosfatídico, el ácido lisofosfatídico y las ceramidas) actúen como importantes inductores de resistencia a la insulina $^{10}$. En particular, el DAG es un potente activador de isoformas clásicas (PKC $\alpha, P K C \beta I, P K C \beta \|$ y $\mathrm{PKC} \gamma)$ y nuevas (PKC $\delta, P K C \varepsilon, \mathrm{PKC} \eta$ y $\mathrm{PKC} \theta)$ de la $\mathrm{PKC}^{11}$. En contraste con la activación aguda de la PKC en respuesta a estímulos específicos, diversos estudios han reportado la activación crónica de una o más isoformas de PKC en células o tejidos en los cuales los valores de DAG se encuentran elevados en el largo plazo. Así, las isoformas clásicas y nuevas de PKC activadas de esta manera participan en la regulación negativa de la señalización de la insulina, en especial por fosforilar a IRS-1 en residuos de serina $^{12}$. Se ha demostrado que el aumento en los valores de DAG, por un incremento en plasma de los AGL, promueve la activación de $\mathrm{PKC} \beta \|$ y $\mathrm{PKC} \delta$ en el músculo esquelético de los humanos. La activación de ambas isoformas se ha asociado a la fosforilación del receptor de insulina y del IRS, lo que conlleva una disminución en el estado de fosforilación en tirosinas en ambas proteínas, afectando su señalización ${ }^{13}$ (Fig. 2).

En el tejido hepático de animales con una dieta alta en grasa, la resistencia a la insulina se ha asociado a un incremento en los valores de DAG que promueve la translocación de la PKC $\varepsilon$ a la membrana plasmática, donde interacciona con el dominio catalítico del receptor de insulina. Esta interacción promueve la disminución de la actividad del receptor, afectando la fosforilación en tirosinas de IRS-2 y la actividad de $A k t 2^{14}$. Consecuentemente, la capacidad de la 


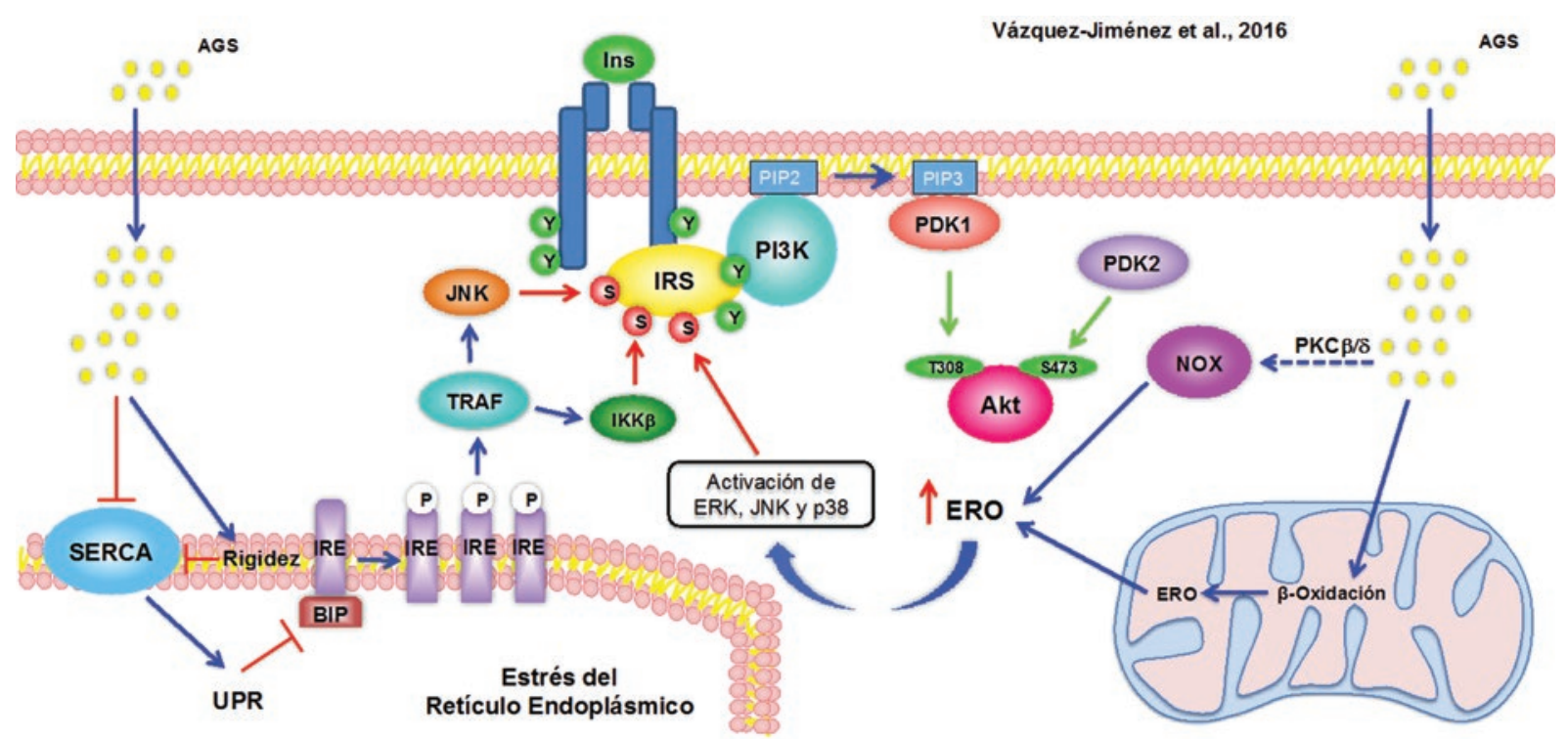

Figura 3. Resistencia a la insulina inducida por AGS a través de estrés del retículo y estrés oxidativo. Los AGS provocan un aumento en el estado de estrés oxidativo por el incremento en la $\beta$-oxidación. Adicionalmente, los AGS pueden activar a la PKC $\beta$, la cual induce la activación de la NOX y la producción de ERO. Una vez establecido, el estrés oxidativo activa múltiples cinasas de serina, como JNK, ERK y p38, las cuales fosforilan a IRS. Por otra parte, los AGS también promueven estrés del RE. Uno de los mecanismos propuestos sugiere que la disminución de la fluidez membranal, por la síntesis de lípidos de membrana a partir de AGS, afecta la actividad de la bomba SERCA y las concentraciones de $\mathrm{Ca}^{2+}$, Ilevando a estrés del retículo. Esta condición desencadena la UPR, involucrada en la activación de IRE-1, que a través de su interacción con TRAF2 lleva a la activación de las cinasas IKKß y JNK, las cuales a su vez fosforilan a IRS. La fosforilación de IRS en residuos de serina se ha asociado a una disminución en su estado de fosforilación en tirosinas, lo que reduce su capacidad para interactuar con otras proteínas de señalización, alterándose principalmente la vía de PI3K/Akt (modificada del abstract gráfico de Vázquez-Jiménez JG, et al. ${ }^{71}$ ). AGS: ácidos grasos saturados; Akt: proteína cinasa B; BIP: proteína de unión a inmunoglobulinas; ERK1/2: proteínas cinasas reguladas por señales extracelulares 1/2; ERO: especies reactivas de oxígeno; Ins: insulina; IKK $\beta$ : cinasa de IK $\beta$; IRE: endonucleasa que requiere inositol; IRS: sustrato del receptor de insulina; JNK: cinasa aminoterminal de c-Jun; p38: proteína cinasa activada por mitógenos de 38 KDa; PDK1: proteína cinasa dependiente de fosfoinositidos 1; PDK2: cinasa dependiente de fosfoinositidos 2; PI3K: cinasa de fosfatidilinositol 3; PIP2: fosfatidilinositol-4,5-bifosfato; PIP3: fosfatidilinositol-3,4,5-trisfosfato; S: serina; SERCA: ATPasa de Ca2+ del retículo sarco/endoplásmico; T: treonina; TRAF: factor asociado al receptor de TNF- $\alpha$; UPR: respuesta de proteínas mal plegadas; Y: tirosina.

insulina de activar la síntesis de glucógeno y de inhibir la gluconeogénesis se encuentra alterada ${ }^{15}$. Es interesante que el incremento en los valores de DAG y su asociación con la activación de la PKCE fueron los mejores marcadores de resistencia a la insulina en tejido hepático de humanos obesos ${ }^{16,17}$.

Por otro lado, en células musculares $\mathrm{C} 2 \mathrm{C} 12$, altas concentraciones de ácido palmítico favorecieron el incremento del DAG y la consecuente activación de PKC $\theta$, que una vez activa fosforila a IRS-1 en la serina 307, bloqueando así la vía de señalización de la insulina $^{18}$. En este mismo tipo celular se identificó otro sitio en IRS-1 que es fosforilado por la PKC $\theta$, la serina 1101, por acción del ácido araquidónico ${ }^{19}$. En un estudio reciente, Szendroedi, et al. ${ }^{20}$ demostraron que la inducción aguda de resistencia a la insulina por infusión de lípidos en individuos sanos y delgados se relaciona con un incremento transitorio en el contenido citosólico de DAG en el músculo esquelético, que fue temporalmente asociado con la activación de PKC $\theta$, un aumento en la fosforilación de la serina 1101 y la inhibición de la fosforilación en tirosina de IRS-1, así como la inactivación de Akt2 inducida por insulina. El incremento en el contenido de DAG en el tejido muscular, la activación de la PKC $\theta$ y la resistencia a la insulina también se observaron en individuos obesos sanos y en pacientes obesos con DM220.

Por otra parte, Pereira, et al. ${ }^{21}$ demostraron in vivo que en células hepáticas la resistencia a la insulina inducida por AGL se desarrolla por estrés oxidativo, generado por la oxidasa de NADPH (NOX) a través de un mecanismo dependiente de PKC $\delta$. El estrés oxidativo lleva a la activación de cinasa de IKB (IKK $\beta)$ y JNK, cinasas que median la fosforilación en serina de IRS-1 e IRS-2, con la consecuente alteración de la señalización de insulina ${ }^{21}$ (Fig. 3).

De los resultados obtenidos por varios grupos de investigación se sugiere que la principal diana de regulación en la señalización de la insulina por la PKC es IRS. Sin embargo, en un estudio realizado por Wang, et al. ${ }^{22}$ se demostró que el ácido palmítico, a 
través de la activación de la PKC $\theta$, induce la fosforilación de PDK1 en la serina 504/505, lo que altera su actividad enzimática y afecta la posterior activación de Akt (Fig. 2). Adicionalmente, se evidenció que los AG atenúan la actividad del regulador transcripcional del receptor de insulina, HGMA1, a través de un mecanismo que involucra la activación de la PKCE por palmitoilación. Este mecanismo reduce la expresión del receptor y de manera significativa la sensibilidad a la insulina ${ }^{23}$.

\section{Ceramidas y resistencia a la insulina}

Otros intermediarios del metabolismo de los AGL involucrados en la patogénesis de la resistencia a la insulina son las ceramidas, que pueden acumularse en las células por dos vías principales: la hidrólisis de esfingomielina de la membrana celular, por acción de la enzima esfingomielinasa ${ }^{24,25}$, o por su síntesis de novo a partir de AGS de cadena larga como el ácido palmítico, que implica una ruta biosintética de múltiples pasos que ocurre en el $\mathrm{RE}^{24,26}$. A la fecha se ha identificado que diferentes factores, como el factor de necrosis tumoral alfa (TNF- $\alpha$ ), endotoxinas y diversos estímulos de estrés, activan a la esfingomielinasa, lo que conduce a la generación de ceramidas $^{24,25}$.

Se ha demostrado que la acumulación de ceramidas, asociada principalmente al incremento en la concentración de ácido palmítico, puede afectar la activación de Akt2 inducida por insulina. Lo anterior parece deberse a un efecto directo sobre la activación de Akt2, y no por interferir en la señalización de proteínas que se activan antes de esta cinasa ${ }^{27,28}$. En primer lugar, se ha descrito que las ceramidas promueven la activación de la fosfatasa de proteína $2 \mathrm{~A}$ (PP2A). La PP2A es una fosfatasa citoplasmática de serina/treonina que se expresa de manera ubicua y tiene un papel importante en la regulación de diversos procesos celulares, entre ellos la regulación de enzimas metabólicas, de receptores para hormonas, de cascadas de cinasas y del crecimiento celular. Bajo condiciones fisiológicas, la insulina inhibe a la PP2A. Se ha demostrado que la PP2A desfosforila la treonina 308 de Akt, que es uno de los dos residuos que, junto con la serina 473 , se encuentran fosforilados cuando la enzima está activa ${ }^{29}$ (Fig. 2). Adicionalmente, las ceramidas impiden el reclutamiento de Akt a la membrana celular al activar a la PKC atípica $\zeta$ (PKC $)$ ), la cual fosforila a la treonina 34 , que se encuentra en el dominio $\mathrm{PH}$ de Akt, previniendo su unión a $\mathrm{PIP}_{3} \mathrm{e}$ inhibiendo su translocación y su subsecuente activación en respuesta a la insulina ${ }^{30,31}$ (Fig. 2).

En la actualidad existe controversia sobre la importancia del papel que desempeñan las ceramidas en la resistencia a la insulina, debido a las diferencias en los resultados obtenidos: en algunos estudios se ha encontrado una correlación directa entre la acumulación de ceramidas y la resistencia a la insulina, pero en otros se sugiere que los AGS promueven resistencia a la insulina por el incremento en las concentraciones de DAG, sin cambios significativos en el contenido de ceramidas ${ }^{32,33}$.

\section{Ácidos grasos, estrés oxidativo y resistencia a la insulina}

El estrés oxidativo se puede definir como un estado de desequilibrio entre la producción y la eliminación de ERO, cuya sobreproducción por un incremento en las concentraciones plasmáticas de AGL promueve un estado de estrés oxidativo que se ha asociado a daño mitocondrial y a diferentes procesos fisiopatológicos, como la resistencia a la insulina, la obesidad y la diabetes ${ }^{34}$. En el caso de la obesidad, los AGL liberados por el tejido adiposo dañado como consecuencia de su expansión y del desarrollo de hipoxia y muerte celular, son metabolizados por los tejidos muscular y hepático en los que se ha identificado sobreproducción de ERO y el desarrollo de estrés oxidativo ${ }^{35}$. En sujetos sanos, la infusión de AGL causa un incremento del estrés oxidativo y de la resistencia a la insulina que puede revertirse con antioxidantes ${ }^{36}$. Por su parte, el incremento de los AGL en la obesidad provoca un aumento en el estado de estrés oxidativo a través del incremento en la $\beta$-oxidación de los ésteres de acil coenzima $A$ de cadena larga, la forma metabólicamente activa de los $\mathrm{AGL}^{37}$ (Fig. 3). Además, se ha descrito que, en células de músculo liso de aorta y en células endoteliales, los AGL como el ácido palmítico también pueden estimular la producción de ERO a través de la activación de la NOX, la cual promueve estrés oxidativo por un mecanismo dependiente de $\operatorname{PKC} \beta^{38,39}$ (Fig. 3). Se ha sugerido que la PKC induce la activación de la NOX por la fosforilación de las subunidades $p 47^{\text {phox }}$, p6 $7^{\text {phox }}$ y Rac, provocando su translocación al heterodímero Nox2/p22phox, que finalmente conlleva la formación del complejo activo de $\mathrm{NOX}^{38,39}$.

La producción de ERO y el estrés oxidativo activan múltiples vías de señalización sensibles al estrés, en las que participan cinasas miembros de la familia de 
MAPK, como JNK, ERK y p38. Estas cinasas promueven la fosforilación del receptor de insulina y de IRS, lo cual se asocia a una reducción en su estado de fosforilación en tirosina y a la atenuación de la señal de insulina ${ }^{40}$ (Fig. 3). Nakamura, et al. ${ }^{41}$ demostraron que, en la línea celular de origen hepático H4IIEC3, el ácido palmítico inhibe el efecto de la insulina sobre la fosforilación en tirosina de IRS-2 y de Akt, a través de un mecanismo que involucra la activación de JNK. Encontraron que la activación de JNK se asocia al incremento en la $\beta$-oxidación generada por el ácido palmítico, lo cual causa un exceso en el flujo de electrones en la cadena respiratoria y un incremento en la generación de ERO producidas en la mitocondria. Además, el incremento en la fosforilación oxidativa se asoció a un aumento en la expresión de la enzima carnitina palmitoiltransferasa 1a, que es limitante en la $\beta$-oxidación de $A G$ mitocondrial ${ }^{41}$.

También se ha evidenciado que el estrés oxidativo estimula la activación de factores transcripcionales, como el factor nuclear kappa B (NFkB), la proteína activadora 1 (AP-1) y el factor inducible por hipoxia 1 (HIF-1), que promueven la expresión génica de factores proinflamatorios ${ }^{40}$. Furukawa, et al. ${ }^{42}$ demostraron que la acumulación de grasa en humanos y ratones con obesidad se correlaciona con la presencia de estrés oxidativo sistémico. Estos autores observan que en el tejido adiposo de ratones obesos se incrementa la producción de ERO, y que esto se asocia con un aumento en la expresión de la NOX y una disminución de la expresión de enzimas antioxidantes. Además, en células adiposas en cultivo, los AG estimulan la actividad de la NOX y promueven el incremento de adipocitocinas, como el inhibidor del activador del plasminógeno-1, la interleucina 6, el TNF- $\alpha$ y la proteína quimiotáctica de monocitos 1 . Estas citocinas proinflamatorias, por una parte, contribuyen al estado local y generalizado de la inflamación asociada a la obesidad, y por otra inducen directamente resistencia a la insulina ${ }^{1,43}$.

Cabe señalar la observación de que en un estado crónico de exceso de AGL, se presenta disfunción de las células beta pancreáticas. En este contexto, la exposición prolongada de estas últimas a AGL provo$\mathrm{ca}$, por una parte, un aumento en los valores basales de liberación de insulina, y por otra la inhibición de su secreción inducida por glucosa ${ }^{44}$. Además, inhiben la expresión génica de insulina e inducen apoptosis en éstas células ${ }^{45,46}$. Se ha sugerido que la alteración sobre las funciones de las células beta puede deberse a la producción de ERO y al estado de estrés oxidativo, tanto en modelos animales como en estudios realizados en humanos ${ }^{47-49}$.

\section{Papel de los ácidos grasos en el estrés del retículo endoplásmico}

Nuevas evidencias establecen que la disfunción del RE contribuye al desarrollo de enfermedades metabólicas, como la obesidad y la DM2. El RE desempeña un papel determinante en la homeostasis del $\mathrm{Ca}^{2+}$ y participa en la maduración y la expresión de proteínas de membrana y de secreción. En condiciones de estrés celular que incrementan la demanda del RE y que conllevan una sobrecarga de su capacidad funcional se genera una serie de alteraciones conocidas como "estrés del retículo", que incluyen la disminución del transporte de proteínas hacia el aparato de Golgi, la expresión de proteínas mal plegadas y la depleción del calcio de este reservorio ${ }^{50}$. Bajo estas condiciones, el RE activa un mecanismo compensatorio denominado «respuesta de proteínas mal plegadas" (UPR, unfolding protein response), que intenta restablecer la homeostasis de las funciones del $R^{50}$. En caso de que esta respuesta sea insuficiente, se desencadena entonces apoptosis ${ }^{51}$.

La UPR dispara la activación de tres enzimas sensoras de estrés: 1) la cinasa de proteína del retículo parecida a la cinasa que se activa por ARN de doble cadena (PERK); 2) la enzima endorribonucleasa que requiere inositol-1 (IRE-1); y 3) el precursor del factor de transcripción 6 (ATF6). Bajo condiciones normales, estas proteínas se asocian, a través de su dominio luminal, con la chaperona BIP/GPR78 (proteína de unión a inmunoglobulinas/proteína regulada por glucosa 78), permaneciendo de esta forma inactivas. En condiciones de estrés, BIP/GPR78 se separa de las enzimas sensoras para promover el correcto plegamiento proteico. Adicional a la separación de BIP, se activan las tres proteínas sensoras, las cuales favorecen la expresión de proteínas que ayudan con la sobrecarga de proteínas y de enzimas asociadas con la degradación de proteínas en el retículo ${ }^{51,52}$.

Por otro lado, la activación de IRE-1 induce su interacción con la proteína TRAF, mecanismo que favorece la activación de las cinasas IKK $\beta$ y JNK, que a su vez pueden fosforilar a IRS1 en residuos de serina bloqueando la vía de señalización de la insulina $^{52}$ (Fig. 3). En respuesta a la conversión de cantidades excesivas de AGL y otros nutrientes en grasa, las células adiposas pueden desarrollar signos de estrés del RE (Fig. 3). Estudios in vitro en cultivos 
de células adiposas ${ }^{53,54}$, hepáticas ${ }^{55}$ y beta pancreáticas $^{56}$ han demostrado que los AGL producen estrés del RE y UPR. Por otra parte, el incremento en AGL por una dieta alta en grasa o por la infusión de lípidos provoca estrés del RE en tejido adiposo y hepático de roedores ${ }^{54,57}$. Se demostró que, mientras el estrés del RE produce resistencia a la insulina principalmente a través de la activación de JNK, la sobreexpresión de la chaperona OPR150 en ratones diabéticos (db/db), o el pretratamiento con chaperonas químicas, disminuye la activación de JNK, lo cual sugiere que la protección de las células frente al estrés del RE disminuye el estado de resistencia a la insulina ${ }^{51,58-60}$.

De acuerdo con lo anterior, la cinasa JNK ha surgido como un regulador clave de las alteraciones metabólicas en la sensibilidad a la insulina. Se ha detectado que la actividad de JNK se encuentra elevada en modelos animales de obesidad ${ }^{58,60}$, y la deleción de las isoformas 1 y 2 de JNK protege a los ratones de la resistencia a la insulina inducida por una dieta alta en grasa ${ }^{61,62}$. En investigación molecular, evidencias experimentales indican que JNK fosforila por una parte a IRS-1 en la serina 307, fosforilación que se ha asociado a la disminución de las acciones de la insulina por alterar la asociación entre el receptor de insulina e IRS-163,64, y por otra fosforila a IKK $\beta$ que lleva a la activación del NFKB y a la regulación de las respuestas inflamatorias ${ }^{50,65}$.

Además de la fosforilación de IRS mediada por JNK, existen otros mecanismos asociados con la resistencia a la insulina inducida por el estrés del RE. Uno que puede ser importante y relevante es la activación de la fosfatasa de tirosina-1B (PTP1B). Esta enzima, que se encuentra anclada a la superficie membranal de la cara citosólica del RE a través del extremo carboxilo-terminal, actúa como un regulador negativo de las acciones de la insulina y de IRS-166. Recientemente se demostró que una dieta alta en grasa induce la expresión de proteínas marcadoras de la UPR, así como de la PTP1B en músculo esquelético, incremento que fue prevenido por el tratamiento con la chaperona química TUDCA (ácido tauroursodesoxicólico) que reduce el estrés del $\mathrm{RE}^{66}$. Controversialmente, Obanda y Cefalu ${ }^{67}$ demostraron que el incremento en la expresión de la PTP1B por los AGL per se no tiene un papel directo en la resistencia a la insulina. Proponen que el incremento en los valores de ceramidas por el metabolismo de los AGL en células musculares se asocia con una alterada activación de Akt, la cual regula negativamente la actividad de la PTP1B por la fosforilación en la serina
50, disminuyendo por tanto la fosforilación de este residuo e incrementando la actividad de la PTP1B, lo que promueve resistencia a la insulina ${ }^{67}$.

Por otra parte, alteraciones en la expresión de la ATPasa de $\mathrm{Ca}^{2+}$ del retículo sarco/endoplásmico (SERCA), que tienen como función eliminar el calcio del citosol y devolverlo al RE, se asocian al desarrollo de estrés del RE y posteriormente a resistencia a la insulina. Bajo condiciones que reducen la actividad de la bomba SERCA se produce un ambiente de calcio luminal que conlleva la baja actividad de las chaperonas del retículo ${ }^{68}$. En el año 2010, Park, et al. ${ }^{69}$ reportaron que en tejido hepático de ratones obesos (ob/ob) se presenta una reducción importante de la expresión de SERCA en comparación con ratones control; la restauración de la bomba en este tejido se asocia con una disminución del estrés del RE, un incremento en la tolerancia a la glucosa y una disminución en la glucemia ${ }^{69}$. Por otro lado, en células hepáticas, el ácido palmítico promueve estrés del RE, alterándose de manera drástica la actividad de SER$\mathrm{CA}$ y las concentraciones de $\mathrm{Ca}^{2+}$ en el RE, y llevando a la muerte celular ${ }^{70}$. Recientemente demostramos que, en células de origen endotelial, el ácido palmítico induce resistencia a la insulina a través de un mecanismo bifásico, que involucra un incremento inicial transitorio seguido de una reducción mantenida de los valores proteicos de SERCA. A pesar de ello, el ácido palmítico produjo una inhibición mantenida de la actividad ATPasa de la bomba. De manera interesante, la resistencia a la insulina apareció antes de que existiera una reducción de la expresión de SERCA. La activación de las cinasas PERK y JNK por el ácido palmítico sugiere que el mecanismo por el que el ácido altera la señalización de la insulina involucra al estrés del retículo. La sobreexpresión de SERCA revirtió el efecto del ácido palmítico sobre la señalización de la insulina, indicando que la reducción de su expresión y de su actividad sería la causa de que el ácido palmítico induzca un estado de resistencia en las células endoteliales ${ }^{71}$.

El tratamiento de las personas diabéticas con rosiglitazona, un fármaco antidiabético, incrementó la expresión de SERCA, restaurando la reducción de la expresión de la bomba observada en pacientes diabéticos con hiperglucemia alterada ${ }^{72}$. El empleo de la chaperona química TUDCA restaura la expresión y la actividad de la bomba SERCA en ratones obesos (ob/ $o b)^{73}$. De esta forma, la disminución de la expresión de SERCA promueve el desarrollo de estrés del RE, con la consecuente activación de JNK que 
desensibiliza la señal de insulina, generando un estado de resistencia a la insulina y contribuyendo al deterioro metabólico crónico.

\section{Rigidez membranal y la resistencia a la insulina}

Diversos reportes han evidenciado que los tipos de $A G$ en la dieta determinan el tipo de $A G$ que se encuentran disponibles para la composición de las membranas celulares. Las membranas que contienen fosfolípidos sintetizados a partir AGS presentan una estructura distinta y menos fluida que aquellas que incorporan AG poliinsaturados (o esenciales) ${ }^{74,75}$. Se ha propuesto que el grado de fluidez membranal, determinado por la relación de AG poliinsaturados y AGS, tiene influencia en la efectividad de la incorporación de glucosa dependiente de insulina y de transportadores GLUT4, y de la unión de la insulina a su receptor ${ }^{75-77}$. Diferentes estudios experimentales concuerdan en señalar que la composición de $A G$ en los fosfolípidos membranales de células musculares influye de manera importante en la sensibilidad a la insulina ${ }^{75,77,78}$.

Más allá de las alteraciones en la membrana celular generadas por la incorporación de los AGS a los fosfolípidos, se han observado también cambios en la composición lipídica de las membranas del RE y de la mitocondria que afectan la función de estos organelos. En el caso del RE, la fluidez de la membrana es muy importante para su actividad fusogénica y su plasticidad. Borradaile, et al. ${ }^{79}$ demostraron que la incubación con AGL causa estrés del RE, efecto que se asoció con una mayor proporción de triglicéridos con AGS en su membrana en comparación con los triglicéridos en células control, y ello puede asociarse a una disminución de la fluidez de la membrana del RE. Por otra parte, se ha demostrado que concentraciones fisiopatológicas de colesterol disminuyen la fluidez membranal, así como la actividad de la bomba SER$C A$, efecto que no se presenta cuando existen altas concentraciones de $A G$ insaturados en la membrana del RE. Estos datos sugieren que, si se disminuye la fluidez de la membrana del RE, eventualmente se desarrollará estrés del retículo, que a su vez podría generar un estado de resistencia a la insulina ${ }^{80}$ (Fig. 3).

En la membrana mitocondrial, la composición de AG y el grado de saturación de los fosfolípidos son de importancia para su fluidez, su permeabilidad y, por lo tanto, su apropiada función ${ }^{81}$. Se ha sugerido que el consumo de una dieta alta en grasas puede influir en la composición de la membrana mitocondrial, lo cual se ha asociado a alteraciones que conllevan resistencia a la insulina y DM2 ${ }^{82,83}$. Sin embargo, datos recientes de Hoeks, et al. ${ }^{84}$ sugieren que, aunque en ratones con una dieta alta en grasa se promueven cambios en la composición lipídica de la membrana mitocondrial, no se observan alteraciones de las funciones mitocondriales, como la oxidación de AG, a pesar de que sí se induce resistencia a la insulina. De hecho, otros estudios han sugerido que la capacidad mitocondrial en el músculo esquelético se encuentra incrementada en roedores con una dieta alta en grasa ${ }^{85-87}$. Estos hallazgos ponen de manifiesto la necesidad de más estudios que clarifiquen la importancia de la composición de la membrana mitocondrial en las funciones mitocondriales y su asociación con el desarrollo de resistencia a la insulina.

\section{Resistencia a la insulina mediada por receptores tipo Toll}

Se ha demostrado que el incremento en los valores de glucosa, de AGL y de secreción de citocinas proinflamatorias en la DM2 tienen importantes implicaciones para el sistema inmunitario ${ }^{88,89}$. Estudios en modelos animales y en humanos han sugerido un vínculo estrecho entre la DM2 y los cambios en la respuesta del sistema inmunitario innato ${ }^{90}$. En este sentido, los receptores tipo Toll (TLR), una familia de receptores transmembrana que pertenecen al sistema inmunitario innato y que reconocen patrones moleculares asociados a patógenos, tienen una participación importante en la patogénesis de la resistencia a la insulina, la inflamación y la DM288,89,91. En particular, los TLR-4 presentan una elevada expresión y señalización en roedores y humanos con obesidad y resistencia a la insulina, principalmente en tejidos diana de la insulina ${ }^{91-93}$. Aunque los mecanismos por los que la señalización de los TLR-4 se encuentra incrementada, aún se han definido por completo, una posible explicación es que los valores de lipopolisacáridos, el ligando natural de los TLR-4, se encuentran elevados en individuos con obesidad y DM2 ${ }^{94,95}$. De manera interesante, se reportó que los AGS también son agonistas de los TLR-4, lo que sugiere un posible papel de estos receptores en la inflamación crónica inducida por la obesidad ${ }^{96}$. La activación de la señalización mediada por TLR-4 promueve la generación de citocinas proinflamatorias a través de la sobrerregulación de varios factores transcripcionales, como NF-KB y AP-197 (Fig. 4). De esta forma, la deficiencia de TLR-4 en ratones $\mathrm{KO}$ mejora la sensibilidad a la insulina y atenúa de manera significativa la 


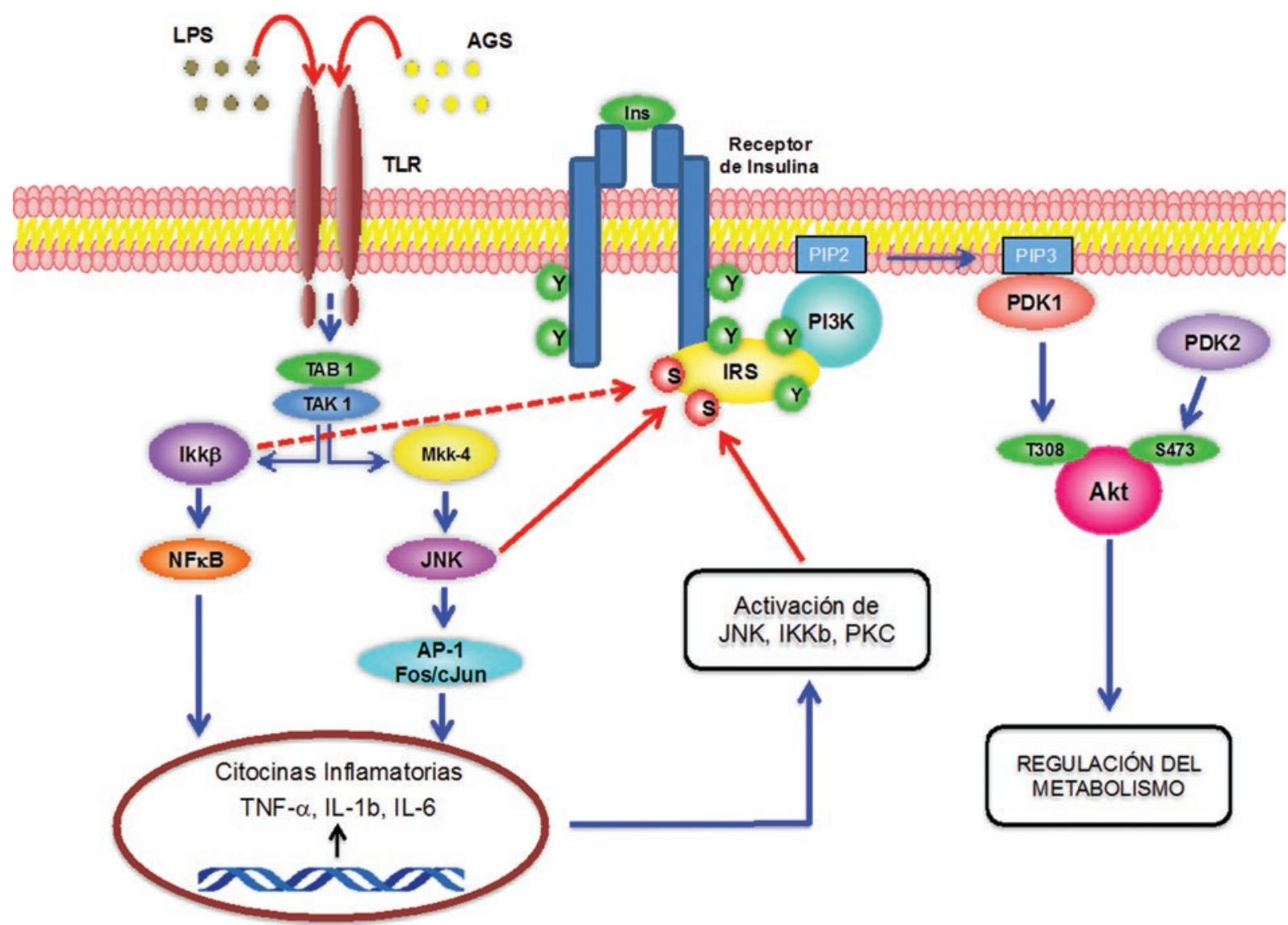

Figura 4. Efectos de los ácidos grasos mediados a través de TLR. La activación de los TLR por LPS o AGS lleva a la asociación de la cinasa TAK1 con la proteína TAB1, complejo que promueve la activación de KKß y JNK causando la fosforilación de IRS e incrementando la transcripción de genes inflamatorios que contribuyen a la resistencia a la insulina, a través de la activación de factores transcripcionales como el NFKB y la AP-1 (modificada de Vázquez-Jiménez JG, et al. ${ }^{71}$ ). AGS: ácidos grasos saturados; Akt: proteína cinasa B; AP-1: proteína activadora 1 formada por Fos/cJun; Fos: proto-oncogén codificado en humanos por el gen fos; Ins: insulina; IKK $\beta$ : cinasa de IK $\beta$; IL-1B: interleucina-1B; IL-6: interleucina 6; IRS: sustrato del receptor de insulina; JNK: cinasa aminoterminal de c-Jun; c-Jun: proto-oncogén codificado por el gen c-jun; LPS: lipopolisacáridos; MKK4: proteína cinasa activada por mitógenos 4; NFKB: factor nuclear kappa B; PDK1: proteína cinasa dependiente de fosfoinositidos 1; PDK2: cinasa dependiente de fosfoinositidos 2; PI3K: cinasa de fosfatidilinositol 3; PIP2: fosfatidilinositol-4,5-bifosfato; PIP3: fosfatidilinositol-3,4,5-trisfosfato; PKC: proteína cinasa C; S: serina; T: treonina; TAK1: proteína cinasa activada por factor de crecimiento transformante beta 1; TAB1: proteína de unión a TAK1; TLR, receptores tipo Toll; TNF- $\alpha$; factor de necrosis tumoral alfa; $Y$, tirosina.

inflamación en estados de obesidad inducida por dieta ${ }^{93,98,99}$. Recientemente, Jia, et al. ${ }^{100}$ demostraron que ratones deficientes en TLR-4 hepático (TIr4L ${ }^{\mathrm{KO}}$ ) muestran un incremento en la sensibilidad a la insulina y una mejora en la tolerancia a la glucosa y la esteatosis hepática, a pesar del desarrollo de obesidad por una dieta alta en grasa. Adicionalmente, estos ratones $\mathrm{KO}$ mostraron una disminución de la respuesta inflamatoria en el tejido adiposo y en los marcadores inflamatorios circulantes $^{100}$. Estos datos refuerzan la idea de que el sistema inmunitario desempeña un papel crucial en el desarrollo de resistencia a la insulina y DM2.

\section{Conclusiones}

El incremento en las concentraciones circulantes de $A G L$, en particular los saturados, en condiciones patológicas como la obesidad, induce resistencia a la insulina a través de diferentes mecanismos descritos en la presente revisión. Resulta por demás interesante que, más allá de los mecanismos clásicos identificados en la resistencia a la insulina, como la fosforilación en residuos de serina en IRS, por acción de diferentes cinasas como PKC, JNK e IKK $\beta$, evidencias recientes sugieren que los AGS pueden regular proteínas que se activan posterior a IRS, a nivel de PDK1 y Akt, así como la expresión de citocinas inflamatorias. Esto indica la complejidad de los mecanismos involucrados en la resistencia a la insulina, la multiplicidad de puntos de regulación y por qué es tan difícil establecer medidas terapéuticas; sin embargo, el adecuado estudio y el entendimiento de tales mecanismos puede aportar una mejor visión sobre los mismos y ampliar las rutas terapéuticas ante esta alteración. 


\section{Agradecimientos}

JGVJ fue becario del CONACYT (No. 233232). ARG es becaria del CONACYT (No. 245147). Este trabajo fue apoyado por el fondo sectorial SEP/CONACYT (Clave 167673). También se agradecen a Diego Olivares Hernández la revisión y las sugerencias para mejorar la redacción del texto.

\section{Conflictos de intereses}

\section{Los autores declaran no tener ningún conflicto de intereses.}

\section{Bibliografía}

1. Olivares-Reyes JA. Bases moleculares del síndrome metabólico y resistencia a la insulina. En: Garibay-Nieto S, editor. Obesidad en la edad pediátrica: prevención y tratamiento. Mexico, D.F.: Corinter; 2012. p. 185-214

2. Kahn SE, Hull RL, Utzschneider KM. Mechanisms linking obesity to insulin resistance and type 2 diabetes. Nature. 2006;444:840-6.

3. Karpe F, Dickmann JR, Frayn KN. Fatty acids, obesity, and insulin resistance: time for a reevaluation. Diabetes. 2011;60:2441-9.

4. Jensen M, De Meyts P. Molecular mechanisms of differential intracellular signaling from the insulin receptor. Vitam Horm. 2009;80:51-75.

5. Nelson DL, Cox MM. Lehninger principles of biochemistry. $6^{\text {th }}$ ed. New York, USA: MacMillan; 2013.

6. Legrand-Poels S, Esser N, L'homme L, et al. Free fatty acids as modulators of the NLRP3 inflammasome in obesity/type 2 diabetes. Biochem Pharmacol. 2014:92:131-41.

7. Rachek LI. Free fatty acids and skeletal muscle insulin resistance. Prog Mol Biol Transl Sci. 2014;121:267-92.

8. Randle PJ, Garland PB, Hales CN, et al. The glucose fatty-acid cycle its role in insulin sensitivity and the metabolic disturbances of diabetes mellitus. Lancet. 1963;281:785-9.

9. Lewis GF, Carpentier A, Adeli K, et al. Disordered fat storage and mobilization in the pathogenesis of insulin resistance and type 2 diabetes. Endocr Rev. 2002;23:201-29.

10. Capurso C, Capurso A. From excess adiposity to insulin resistance: the role of free fatty acids. Vascul Pharmacol. 2012;57:91-7.

11. Farese RV. Protein kinase C. En: LeRoith D, Taylor SI, Olefsky JM, editores. Diabetes mellitus: a fundamental and clinical text. $3^{\text {rd }}$ ed. Philadelphia, USA: Lippincott; 2000. p. 301-16.

12. Schmitz-Peiffer $C$. The tail wagging the dog - regulation of lipid metabolism by protein kinase C. FEBS J. 2013;280:5371-83.

13. Youngren J. Regulation of insulin receptor function. Cell Mol Life Sci. 2007;64:873-91.

14. Samuel VT, Liu ZX, Wang A, et al. Inhibition of protein kinase $C$ epsilon prevents hepatic insulin resistance in nonalcoholic fatty liver disease. J Clin Invest. 2007;117:739-45.

15. Samuel VT, Liu ZX, Qu X, et al. Mechanism of hepatic insulin resistance in non-alcoholic fatty liver disease. J Biol Chem. 2004;279:32345-53.

16. Kumashiro N, Erion DM, Zhang D, et al. Cellular mechanism of insulin resistance in nonalcoholic fatty liver disease. Proc Natl Acad Sci U S A 2011;108:16381-5.

17. Perry RJ, Samuel VT, Petersen KF, et al. The role of hepatic lipids in hepatic insulin resistance and type 2 diabetes. Nature. 2014:510:84-91.

18. Coll T, Eyre E, Rodríguez-Calvo R, et al. Oleate reverses palmitate-induced insulin resistance and inflammation in skeletal muscle cells. J Biol Chem. 2008;283:11107-16.

19. Li Y, Soos TJ, Li X, et al. Protein kinase $C \theta$ inhibits insulin signaling by phosphorylating IRS1 at Ser1101. J Biol Chem. 2004;279:45304-7.

20. Szendroedi J, Yoshimura T, Phielix E, et al. Role of diacylglycerol activation of $\mathrm{PKC} \theta$ in lipid-induced muscle insulin resistance in humans. Proc Natl Acad Sci. 2014;111:9597-602

21. Pereira S, Park E, Mori Y, et al. FFA-induced hepatic insulin resistance in vivo is mediated by $\mathrm{PKC} \delta$, NADPH oxidase, and oxidative stress. Am J Physiol Endocrinol Metab. 2014;307:E34-E46.

22. Wang C, Liu M, Riojas RA, et al. Protein kinase $C$ theta (PKC theta)-dependent phosphorylation of PDK1 at Ser504 and Ser532 contributes to palmitate-induced insulin resistance. J Biol Chem. 2009;284:2038-44.

23. Dasgupta S, Bhattacharya S, Maitra S, et al. Mechanism of lipid induced insulin resistance: activated PKC epsilon is a key regulator. Biochim Biophys Acta. 2011;1812:495-506.
24. Kolesnick RN, Kronke M. Regulation of ceramide production and apoptosis. Annu Rev Physiol. 1998;60:643-65.

25. Lipina C, Hundal HS. Sphingolipids: agents provocateurs in the pathogenesis of insulin resistance. Diabetologia. 2011;54:1596-607.

26. Yang G, Badeanlou L, Bielawski J, et al. Central role of ceramide biosynthesis in body weight regulation, energy metabolism, and the metabolic syndrome. Am J Physiol Endocrinol Metab. 2009;297:E211-24.

27. Schmitz-Peiffer C, Craig DL, Biden TJ. Ceramide generation is sufficient to account for the inhibition of the insulin-stimulated PKB pathway in C2C12 skeletal muscle cells pretreated with palmitate. J Biol Chem. 1999;274:24202-10.

28. Stratford S, Hoehn KL, Liu F, et al. Regulation of insulin action by ceramide: dual mechanisms linking ceramide accumulation to the inhibition of Akt/protein kinase B. J Biol Chem. 2004;279:36608-15.

29. Resjö S, Göransson O, Härndahl L, et al. Protein phosphatase $2 A$ is the main phosphatase involved in the regulation of protein kinase $B$ in rat adipocytes. Cell Signal. 2002;14:231-8.

30. Powell DJ, Hajduch E, Kular G, et al. Ceramide disables 3-phosphoinositide binding to the pleckstrin homology domain of protein kinase $B$ (PKB)/ Akt by a PKCzeta-dependent mechanism. Mol Cell Biol. 2003;23:7794-808.

31. Fox TE, Houck KL, O'Neill SM, et al. Ceramide recruits and activates protein kinase $\mathrm{C} \zeta(\mathrm{PKC} \zeta)$ within structured membrane microdomains. J Biol Chem. 2007;282:12450-7.

32. Aerts JM, Boot RG, van Eijk M, et al. Glycosphingolipids and insulin resistance. Adv Exp Med Biol. 2011;721:99-119.

33. Lee JS, Pinnamaneni SK, Eo SJ, et al. Saturated, but not n-6 polyunsaturated, fatty acids induce insulin resistance: role of intramuscular accumulation of lipid metabolites. J Appl Physiol. 2006;100:1467-74.

34. Henriksen EJ, Diamond-Stanic MK, Marchionne EM. Oxidative stress and the etiology of insulin resistance and type 2 diabetes. Free Radic Biol Med. 2011;51:993-9

35. Schenk S, Saberi M, Olefsky JM. Insulin sensitivity: modulation by nutrients and inflammation. J Clin Invest. 2008:118:2992-3002.

36. Paolisso G, Giugliano D. Oxidative stress and insulin action: is there a relationship? Diabetologia. 1996;39:357-63.

37. Wojtczak L, Schonfeld P. Effect of fatty acids on energy coupling processes in mitochondria. Biochim Biophys Acta. 1993;1183:41-57.

38. Inoguchi $T$, Li P, Umeda F, et al. High glucose level and free fatty acid stimulate reactive oxygen species production through protein kinase C-dependent activation of $\mathrm{NAD}(\mathrm{P}) \mathrm{H}$ oxidase in cultured vascular cells. Diabetes. 2000;49:1939-45.

39. Chinen I, Shimabukuro M, Yamakawa K, et al. Vascular lipotoxicity: endothelial dysfunction via fatty-acid-induced reactive oxygen species overproduction in obese Zucker diabetic fatty rats. Endocrinology. 2007;148:160-5

40. Rains JL, Jain SK. Oxidative stress, insulin signaling, and diabetes. Free Radic Biol Med. 2011;50:567-75.

41. Nakamura S, Takamura T, Matsuzawa-Nagata N, et al. Palmitate induces insulin resistance in H4IIEC3 hepatocytes through reactive oxygen species produced by mitochondria. J Biol Chem. 2009:284:14809-18.

42. Furukawa $S$, Fujita $T$, Shimabukuro $M$, et al. Increased oxidative stress in obesity and its impact on metabolic syndrome. J Clin Invest. 2004;114: 1752-61.

43. Soumaya K. Molecular mechanisms of insulin resistance in diabetes. En: Ahmad S, editor. Diabetes. New York: Springer; 2013. p. 240-51.

44. Jacqueminet $\mathrm{S}$, Briaud I, Rouault $\mathrm{C}$, et al. Inhibition of insulin gene expression by long-term exposure of pancreatic beta cells to palmitate is dependent on the presence of a stimulatory glucose concentration. Metabolism. 2000;49:532-6

45. Shimabukuro M, Zhou YT, Levi M et al. Fatty acid-induced beta cell apoptosis: a link between obesity and diabetes. Proc Natl Acad Sci U S A. 1998;95:2498-502.

46. Kaneto H, Nakatani $Y$, Kawamori D, et al. Role of oxidative stress, endoplasmic reticulum stress, and c-Jun $\mathrm{N}$-terminal kinase in pancreatic beta-cell dysfunction and insulin resistance. Int J Biochem Cell Biol. 2006;38:782-93

47. Zhang $\mathrm{X}, \mathrm{Bao} \mathrm{Y}, \mathrm{Ke} \mathrm{L}$, et al. Elevated circulating free fatty acids levels causing pancreatic islet cell dysfunction through oxidative stress. J Endocrinol Invest. 2010;33:388-94.

48. Xiao C, Giacca A, Lewis GF. Oral taurine but not N-acetylcysteine ameliorates NEFA-induced impairment in insulin sensitivity and beta cell function in obese and overweight, non-diabetic men. Diabetologia. 2008;51:139-46.

49. Oprescu Al, Bikopoulos G, Naassan A, et al. Free fatty acid-induced reduction in glucose-stimulated insulin secretion: evidence for a role of oxidative stress in vitro and in vivo. Diabetes. 2007:56:2927-37.

50. Guerrero-Hernández A, León-Aparicio D, Chávez-Reyes J, et al. Endoplasmic reticulum stress in insulin resistance and diabetes. Cell Calcium. 2014;56:311-22.

51. Marciniak SJ, Ron D. Endoplasmic reticulum stress signaling in disease. Physiol Rev. 2006;86:1133-49.

52. Salvado L, Palomer X, Barroso E, et al. Targeting endoplasmic reticulum stress in insulin resistance. Trends Endocrinol Metab. 2015;26:438-48.

53. Guo W, Wong S, Xie W, et al. Palmitate modulates intracellular signaling, induces endoplasmic reticulum stress, and causes apoptosis in mouse 
3T3-L1 and rat primary preadipocytes. Am J Physiol Endocrinol Metab. 2007;293:E576-86.

54. Kawasaki N, Asada R, Saito A, et al. Obesity-induced endoplasmic reticulum stress causes chronic inflammation in adipose tissue. Sci Rep. 2012;2:799.

55. Wei $\mathrm{Y}$, Wang D, Topczewski F, et al. Saturated fatty acids induce endoplasmic reticulum stress and apoptosis independently of ceramide in liver cells. Am J Physiol Endocrinol Metab. 2006;291:E275-81.

56. Karaskov E, Scott C, Zhang L, et al. Chronic palmitate but not oleate exposure induces endoplasmic reticulum stress, which may contribute to INS-1 pancreatic $\beta$-cell apoptosis. Endocrinology. 2006;147:3398-407.

57. Boden G. Obesity, insulin resistance and free fatty acids. Curr Opin Endocrinol Diabetes Obes. 2011;18:139-43.

58. Ozcan U, Cao Q, Yilmaz E, et al. Endoplasmic reticulum stress links obesity, insulin action, and type 2 diabetes. Science. 2004;306:457-61.

59. Nakatani $Y$, Kaneto $H$, Kawamori $D$, et al. Involvement of endoplasmic reticulum stress in insulin resistance and diabetes. $J$ Biol Chem. 2005;280:847-51.

60. Ozcan U, Yilmaz E, Ozcan L, et al. Chemical chaperones reduce ER stress and restore glucose homeostasis in a mouse model of type 2 diabetes. Science. 2006;313:1137-40.

61. Hirosumi J, Tuncman G, Chang L, et al. A central role for JNK in obesity and insulin resistance. Nature. 2002;420:333-6.

62. Tuncman G, Hirosumi J, Solinas G, et al. Functional in vivo interactions between JNK1 and JNK2 isoforms in obesity and insulin resistance. Proc Natl Acad Sci U S A. 2006;103:10741-6.

63. Aguirre V, Werner ED, Giraud J, et al. Phosphorylation of Ser307 in insulin receptor substrate- 1 blocks interactions with the insulin receptor and inhibits insulin action. J Biol Chem. 2002;277:1531-7.

64. Hotamisligil GS, Peraldi P, Budavari A, et al. IRS-1-mediated inhibition of insulin receptor tyrosine kinase activity in TNF-alpha- and obesity-induced insulin resistance. Science. 1996;271:665-8.

65. Bakker W, Eringa EC, Sipkema P, et al. Endothelial dysfunction and diabetes: roles of hyperglycemia, impaired insulin signaling and obesity. Cell Tissue Res. 2009;335:165-89.

66. Panzhinskiy $E$, Hua $Y$, Culver $B$, et al. Endoplasmic reticulum stress upregulates protein tyrosine phosphatase $1 \mathrm{~B}$ and impairs glucose uptake in cultured myotubes. Diabetologia. 2013;56:598-607.

67. Obanda DN, Cefalu WT. Modulation of cellular insulin signaling and PTP1B effects by lipid metabolites in skeletal muscle cells. J Nutr Biochem. 2013;24:1529-37.

68. Caspersen C, Pedersen PS, Treiman M. The sarco/endoplasmic reticulum calcium-ATPase $2 b$ is an endoplasmic reticulum stress-inducible protein. J Biol Chem. 2000;275:22363-72.

69. Park SW, Zhou Y, Lee J, et al. Sarco(endo)plasmic reticulum Ca2+-ATPase $2 \mathrm{~b}$ is a major regulator of endoplasmic reticulum stress and glucose homeostasis in obesity. Proc Natl Acad Sci U S A. 2010;107:19320-5.

70. Zhang J, Li Y, Jiang S, et al. Enhanced endoplasmic reticulum SERCA activity by overexpression of hepatic stimulator substance gene prevents hepatic cells from ER stress-induced apoptosis. Am J Physiol Cell Physiol. 2014;306:C279-90

71. Vázquez-Jiménez JG, Chávez-Reyes J, Romero-García T, et al. Palmitic acid but not palmitoleic acid induces insulin resistance in a human endothelial cell line by decreasing SERCA pump expression. Cell Signal. 2016;28:53-9

72. Randriamboavonjy V, Pistrosch F, Bolck B, et al. Platelet sarcoplasmic endoplasmic reticulum $\mathrm{Ca2+-ATPase}$ and mu-calpain activity are altered in type 2 diabetes mellitus and restored by rosiglitazone. Circulation. 2008;117:52-60.

73. Ceylan-Isik AF, Sreejayan N, Ren J. Endoplasmic reticulum chaperon tauroursodeoxycholic acid alleviates obesity-induced myocardial contractile dysfunction. J Mol Cell Cardiol. 2011;50:107-16.

74. Hussein JS. Cell membrane fatty acids and health. International Journal of Pharmacy and Pharmaceutical Sciences. 2013;5:38-46.

75. Weijers RN. Lipid composition of cell membranes and its relevance in type 2 diabetes mellitus. Curr Diabetes Rev. 2012;8:390-400.

76. Yorek M, Leeney E, Dunlap J, et al. Effect of fatty acid composition on insulin and IGF-I binding in retinoblastoma cells. Invest Ophthalmol Vis Sci. 1989;30:2087-92.

77. Grunfeld C, Baird KL, Kahn CR. Maintenance of 3T3-L1 cells in culture media containing saturated fatty acids decreases insulin binding and insulin action. Biochem Biophys Res Commun. 1981;103:219-26.
78. Borkman M, Storlien LH, Pan DA, et al. The relation between insulin sensitivity and the fatty-acid composition of skeletal-muscle phospholipids. N Engl J Med. 1993;328:238-44.

79. Borradaile NM, Han X, Harp JD, et al. Disruption of endoplasmic reticulum structure and integrity in lipotoxic cell death. J Lipid Res. 2006;47:2726-37.

80. Li Y, Ge M, Ciani L, et al. Enrichment of endoplasmic reticulum with cholesterol inhibits sarcoplasmic-endoplasmic reticulum calcium ATPase-2b activity in parallel with increased order of membrane lipids: implications for depletion of endoplasmic reticulum calcium stores and apoptosis in cholesterol-loaded macrophages. J Biol Chem. 2004; 279:37030-9.

81. Haag M, Dippenaar NG. Dietary fats, fatty acids and insulin resistance: short review of a multifaceted connection. Med Sci Monit. 2005; 11:RA359-67.

82. Sparks LM, Xie H, Koza RA, et al. A high-fat diet coordinately downregulates genes required for mitochondrial oxidative phosphorylation in skeletal muscle. Diabetes. 2005;54:1926-33.

83. Brehm A, Krssak M, Schmid Al, et al. Increased lipid availability impairs insulin-stimulated ATP synthesis in human skeletal muscle. Diabetes. 2006;55:136-40.

84. Hoeks J, Wilde J, Hulshof MF, et al. High fat diet-induced changes in mouse muscle mitochondrial phospholipids do not impair mitochondrial respiration despite insulin resistance. PLoS One. 2011;6:e27274.

85. Hancock CR, Han DH, Chen M, et al. High-fat diets cause insulin resistance despite an increase in muscle mitochondria. Proc Natl Acad Sci U S A. 2008;105:7815-20.

86. Iossa S, Mollica MP, Lionetti L, et al. Skeletal muscle oxidative capacity in rats fed high-fat diet. Int J Obes Relat Metab Disord. 2002;26:65-72.

87. Turner N, Bruce CR, Beale SM, et al. Excess lipid availability increases mitochondrial fatty acid oxidative capacity in muscle: evidence against a role for reduced fatty acid oxidation in lipid-induced insulin resistance in rodents. Diabetes. 2007:56:2085-92.

88. Dasu MR, Devaraj S, Zhao L, et al. High glucose induces toll-like receptor expression in human monocytes: mechanism of activation. Diabetes. 2008:57:3090-8.

89. Schwartz EA, Zhang WY, Karnik SK, et al. Nutrient modification of the innate immune response: a novel mechanism by which saturated fatty acids greatly amplify monocyte inflammation. Arterioscler Thromb Vasc Biol. 2010;30:802-8.

90. Pino SC, Kruger AJ, Bortell R. The role of innate immune pathways in type 1 diabetes pathogenesis. Curr Opin Endocrinol Diabetes Obes. 2010;17:126-30.

91. Song MJ, Kim KH, Yoon JM, et al. Activation of Toll-like receptor 4 is associated with insulin resistance in adipocytes. Biochem Biophys Res Commun. 2006:346:739-45.

92. Reyna SM, Ghosh S, Tantiwong P, et al. Elevated toll-like receptor 4 expression and signaling in muscle from insulin-resistant subjects. Diabetes. 2008;57:2595-602.

93. Shi $\mathrm{H}$, Kokoeva MV, Inouye $\mathrm{K}$, et al. TLR4 links innate immunity and fatty acid-induced insulin resistance. J Clin Invest. 2006;116:3015-25.

94. Cani PD, Amar J, Iglesias MA, et al. Metabolic endotoxemia initiates obesity and insulin resistance. Diabetes. 2007:56:1761-72.

95. Liang H, Hussey SE, Sánchez-Ávila A, et al. Effect of lipopolysaccharide on inflammation and insulin action in human muscle. PLoS One. 2013;8:e63983

96. Lee JY, Sohn KH, Rhee SH, et al. Saturated fatty acids, but not unsaturated fatty acids, induce the expression of cyclooxygenase-2 mediated through Toll-like receptor 4. J Biol Chem. 2001;276:16683-9.

97. Osborn O, Olefsky JM. The cellular and signaling networks linking the immune system and metabolism in disease. Nat Med. 2012;18: 363-74

98. Suganami T, Mieda T, Itoh M, et al. Attenuation of obesity-induced adipose tissue inflammation in $\mathrm{C} 3 \mathrm{H} / \mathrm{HeJ}$ mice carrying a Toll-like receptor 4 mutation. Biochem Biophys Res Commun. 2007;354:45-9.

99. Poggi M, Bastelica D, Gual P, et al. $\mathrm{C} 3 \mathrm{H} / \mathrm{HeJ}$ mice carrying a Toll-like receptor 4 mutation are protected against the development of insulin resistance in white adipose tissue in response to a high-fat diet. Diabetologia. 2007;50:1267-76

100. Jia L, Vianna CR, Fukuda M, et al. Hepatocyte Toll-like receptor 4 regulates obesity-induced inflammation and insulin resistance. Nat Commun. 2014;5:3878. 